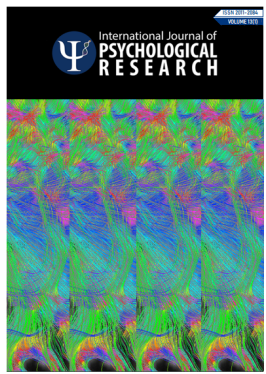

Vol $13, \mathrm{~N}^{\circ} 1$

https://revistas.usb.edu.co/index.php/IJPR ISSN 2011-2084

E-ISSN 2011-7922

\section{Factorial Analysis and Invariance Testing for Age and Gender of the Reactive-Proactive Aggression Questionnaire (RPQ)}

Analisis factorial e invarianza según edad y género del cuestionario The Reactive - Proactive Aggression Questionnaire (RPQ)

Ronald Alberto Toro ${ }^{1 \star}$, Juan García-García ${ }^{1}$, Flor ZaldívarBasurto $^{1}$

${ }^{1}$ Universidad de Almería, Almería, España

\section{OPEN ACCESS}

Editor: Jorge Mauricio Cuartas Arias, Universidad de San Buenaventura, Medellín, Colombia

Manuscript received: $12-07-2019$

Revised: 01-10-2019

Accepted: 02-12-2019.

${ }^{\star}$ Corresponding author:

Ronald Alberto Toro

tororonald@gmail.com,rtt711@inlumine.ual.es

Copyright: @2020. International Journal of Psychological Research provides open access to all its contents under the terms of the license creative commons Attribution-NonCommercialNoDerivatives 4.0 International (CC BY-NCND 4.0)

Declaration of data availability: All relevant data are within the article, as well as the information support files.

Conflict of interests: The authors have declared that there is no conflict of interest.

\begin{abstract}
.
Reactive aggression is characterized by high emotional activation, impulsivity, and hostility, while proactive aggression presents a cold, instrumental, and planned strategy. The aim was to perform a psychometric analysis of the Reactive-Proactive Aggression Questionnaire [RPQ]. A non-probability sample of 502 people between 18 and 40 years old was formed, grouped by sex $(n=297,59.2 \%$ women and $n=205,40.8 \%$ men $)$ and age $(n=224,44.62 \%$ under 25 years old and $n=278,55.38 \%$ over 25 years old). The instruments were the RPQ, the Anger Rumination Scale (ARS), and an affective scale (PANAS) in printed format. In this instrumental psychometric study, we found that the RPQ fits better in a model of two factors interrelated with residual covariances $(C F I=.928$, RMSEA $=.044)$, presenting significant correlations with negative affect and anger rumination, as evidence of validity of concurrent criterion, especially with reactive aggression (anger rumination $r=.542$, and negative affect $r=.359$ ). Also, the test was not invariant between sexes and ages, given that the best fit was in the male sex and those under 25 years of age $(\Delta \mathrm{CFI}<0.01, \Delta \mathrm{RMSEA}<0.015)$. We concluded that women and adults over the age of 25 have a different aggressive response profile. These findings represent new directions of research around the measurement of aggressive behavior and the development of gender differentiated interventions for adolescents and young adults.

Resumen.

La agresión reactiva se caracteriza por una elevada activación emocional, impulsividad y hostilidad, mientras que la agresión proactiva presenta una estrategia fría, instrumental y planificada. El objetivo fue realizar un análisis psicométrico del Reactive-Proactive Aggression Questionnaire [RPQ]. Se conformó una muestra no probabilística de 502 personas entre 18 y 40 años, agrupadas por sexos ( $n=297,59.2 \%$ mujeres y $n=205,40.8 \%$ hombres) y edades ( $n=224,44.62 \%$ menores de 25 años y $n=278,55.38 \%$ mayores de 25 años). Los instrumentos fueron el RPQ, una escala de rumiación-ira (ARS) y una de afecto (PANAS) en formato impreso. En este estudio instrumental psicométrico se encontró que el RPQ se ajusta mejor en un modelo de dos factores interrelacionados con covarianzas residuales (CFI $=.928$, RMSEA $=.044$ ), presenta correlaciones significativas con el afecto negativo y la rumiación-ira, como evidencias de validez de criterio concurrente, en especial con la agresión reactiva (rumiación-ira $r=.542$, y afecto negativo $r=.359$ ). Además, el test no fue invariante entre sexos y edades, dado que el mejor ajuste estuvo en el sexo masculino y menores de 25 años $(\Delta C F I<0.01$, $\triangle$ RMSEA $<0.015)$. Se concluyó que las mujeres y los adultos mayores de 25 años presentan un perfil de respuesta agresiva diferente. Estos hallazgos representan nuevas direcciones de investigación en torno a la medición de la conducta agresiva y el desarrollo de intervenciones diferenciales por sexos para los adolescentes y adultos jóvenes.
\end{abstract}

Keywords.

Aggression, reactive aggression, proactive aggression, factor analysis, invariance.

Palabras Clave.

Agresión, agresión reactiva, agresión proactiva, análisis factorial, invarianza. 


\section{Introduction}

Aggression has been considered a relevant topic in the study of externalizing psychopathologies, because of difficulties in social functioning such as delinquency, violence, substance abuse, among others. The most representative advances in research on underlying motivational, functional, and cognitive mechanisms, have been the ones on classification of proactive and reactive aggression (Penado, Andreu, \& Peña, 2014).

Reactive aggression (RA) is a reaction to a perceived threat, associated with high emotional triggers, impulsivity and hostility, and marked deficiencies in information processing, presenting an intent to harm others without a clear objective (Raine et al., 2006). Anger is one of the emotional responses accompanying this aggression, as well as poor tolerance towards frustration and poor regulation of ambiguous and emotional stimuli (Marsee \& Frick, 2007; Vitaro, Brendgen, \& Tremblay, 2002).

Proactive aggression (PA) presents a cold, instrumental, and planned strategy with clear objectives, aimed at achieving goals (Raine et al., 2006). It often has a controlled response and poor expression of anger without problems with emotional regulation (Hubbard, McAuliffe, Morrow, \& Romano, 2010). A high PA has been identified as associated with a lack of empathy, manipulation of others in favor of oneself, generally in antisocial behavior and psychopathy (White \& Frick, 2010).

Studies on aggression have been reported in people with social incompetence and increases with peer rejection, frequently in men; RA is higher in unpopular people, while it is associated with perceived popularity in PA (Stoltz, Cillessen, van der Berg, \& Gommans, 2016). Also, age has been identified as a moderator for the onset of PA, and in RA derived from internal frustration and external provocation (Smeets et al., 2016). Similarly, high scores in RA and PA indicate a greater propensity to commit violent criminal behavior (Barker, Tremblay, Nagin, Vitaro, \& Lacourse, 2006), although in adolescents, reactive aggressive behaviors are inverse compared to proactive behaviors (Pang, Ang, Kom, Tan, \& Chiang, 2013). Additionally, violent criminal behaviors have been associated with mixed aggressive profiles with high scores in both aggressions (Penado et al., 2014).

Analyzing the combinations between these two types of aggression would allow explaining the underlying motivational mechanisms of criminal and violent behaviors from a perspective based on psychological processes (Crick \& Dodge, 1996; Raine et al., 2006). Further research is needed to broaden this perspective, in particular, measurements of RA and PA based on psychometric instruments recognized for their discriminatory capabilities in different populations.

\subsection{The Instrument in This Study}

The Reactive-Proactive Aggression Questionnaire [RPQ] (Raine et al., 2006) was designed according to reports by teachers on RA and AP, and theoretical conceptualization on these two dimensions (Dodge \& Coie, 1987). We elaborated a set of items oriented towards the physical, verbal, situational, and motivational components of aggression. The results obtained showed significant intercorrelations between RA y PA $(r=.67, p<.0001)$, with which a general model of aggression was proposed (unifactorial), and one of PA and RA (bifactorial oblique). Then, the authors verified the best outcome fit according to the variations when comparing both nested models. In this way, we found that the bifactorial model had the best fit $\left(\Delta \chi^{2}=65\right.$, df $\left.=1, p<.0001\right)$.

The RPQ has had different adaptations in different languages and countries based on this proposal. In Spain, the RPQ was adapted with a Spanish adolescent population (Andreu, Peña, \& Ramírez, 2009). This version obtained a final interrelated solution of two factors with the two types of aggression according to the Goodness of fit index indicators $(\mathrm{GFI}=0.98$ and $\mathrm{AGFI}=0.97)$, and Root mean square residual $(\mathrm{RMR}=0.02)$, unlike the one-dimensional in which aggression is constructed with two poles $(\mathrm{GFI}=0.87, \mathrm{AGFI}=0.89, \mathrm{RMR}=0.06)$.

Currently, different studies have reviewed and obtained a solution of two correlated factors that have demonstrated the best fit, even in cross-cultural validations, findings that support the conceptual differences of PA and RA (e.g. Brugman et al., 2017; Fung, Raine, \& Gao, 2009; Pechorro, Kahn, Ray, Raine, \& Gonçalves, 2017; Tuvblad, Dhamija, Berntsen, Raine, \& Liu, 2016). These differences have not been reported in Latin America to date, particularly in studies of the structural confirmation of this construct, much less on its specific population variations.

In Spain, the RPQ reported favorable indicators for the bifactorial model for men and women, although the comparative scores between groups were significant in men $(F=25.79, p<.001)$, and were not different in ages $(F=0.50, p>.001)$ (Andreu et al., 2009). In Portugal, with a forensic and a community sample of adult women, in which favorable fit indicators were obtained for a correlated two-factor model, this data suggested that male and female samples have differential indicators concerning mixed samples, for example, high PA scores in women (Pechorro et al., 2017).

These differences between male and female sexes have not been analyzed psychometrically in a detailed manner, based on factor structure and invariance, nor with age, given that adults may vary their responses concerning adolescents and young people, without considering the variable contexts such as those in which South American countries may present profiles of aggressive behavior, di- 
fferent from those reported in Anglo-Saxon or North American countries.

Taking into account the above, the hypothesis was to obtain a factorial structure of the RPQ of two interrelated factors, in line with the theoretical proposal and the confirmed versions in different countries, in particular, the Spanish version. A second hypothesis proposed was to obtain test invariance indicators in favor of males who were under 25 years of age, according to previous reports of aggressive behaviors at this stage of the life cycle. A third hypothesis was to obtain significant correlations with measures of negative affection (affective responses associated with guilt, anger, fear, and low levels of calmness and tranquility), particularly associated with anger and rumination-anger (persistent thinking about a personally significant event that occurred to the person or others that leads to the anger response) as predictive variables of aggressive behavior (Peters et al., 2015; White \& Turner, 2014). A fourth hypothesis was to obtain favorable values of internal consistency as reliable indicators of the RPQ, which would make it viable to be used in the context in which the study is carried out.

Thus, the objective of this study was to analyze the factor structure and invariance of the RPQ according to sex and age in a Colombian sample. Although this context does not represent the Latin American idiosyncrasy, it can provide an empirical approximation of the psychometric properties of this population and serves as a starting point for new research on the construction of reactive and proactive aggression once revised. Also, we sought to investigate the validity of concurrent criteria of the RPQ with rumination anger and negative affect (NA) - positive (PAf), as indicators of the test's explanatory capacity, and to investigate the indicators of reliability of the confirmed test.

\section{Method}

\subsection{Participants}

We conducted a non-probabilistic sampling for incidental convenience (5\% error, IC95\%) to select the participants, according to their accessibility or availability and to the criteria of inclusion of the study and the population representativeness of the same, in different contexts with different socioeconomic levels, contacted by direct invitation in their places of work or study. The final sample comprised 502 persons between 18 and 40 years of age, grouped by sex and age, who reported that they were residents of Bogotá and surrounding municipalities. Table 1 shows the final traits of the participants. Among the criteria for inclusion was the voluntary participation in the study, verified with the signature of an informed consent, while we excluded those who had medical and psychiatric alterations and were under the effects of psychoactive substances when responding.

\subsection{Instruments}

Reactive-Proactive Aggression Questionnaire [RPQ]

(Raine et al., 2006). The questionnaire was designed to identify RA, characterized by high emotional activation, impulsivity, and hostility; and PA, characterized by a tendency towards instrumental, planned, non-empathetic, and cold strategy behavior. The questionnaire includes 23 items distributed in 11 for the RA and 12 for the $\mathrm{PA}$, scored on a frequency scale ranging from never (0), sometimes (1), and often (2). Among its Spanish psychometric properties (Andreu et al., 2009), the study showed a favorable Cronbach Alpha Coefficient for the total $(\alpha=.91)$, the RA $(\alpha=.84)$, and the PA $(\alpha=.87)$, with high correlations $(r=.80)$ between the two subscales.

The Anger Rumination Scale [ARS] (Sukhodolsky, Golub, \& Cromwell, 2001). This scale evaluates rumination based on attention focused on thoughts, memories, and past and present experiences of anger, with 19 items on a Likert scale, ranging from 1 ("Rarely") to 4 ("Almost always"), grouped into four factors: Revenge thoughts ( 4 items, $\alpha=.72$ ), thoughts after anger (6 items, $\alpha=.86$ ), anger memories ( 5 items, $\alpha=.85$ ), and understanding causes ( 4 items, $\alpha=.77$ ). The Spanish version (Ortega-Andrade, Alcázar-Olán, Matías, RiveraGuerrero, \& Domínguez-Espinosa, 2017) presented similar alpha coefficients to the original $(\alpha=.72$ and $\alpha=.89)$. Internal consistencies obtained for the ARS in this study were favorable $(\alpha=.92$ and $\omega=.92)$.

\section{Positive and Negative Affect Schedule [PANAS]}

(Watson, Clark, \& Tellegen, 1988). This scale was designed to evaluate negative and positive affects using 20 combined items, 10 items for each dimension, with a Likert format with a range of one (very little) to five (extremely), according to the affective states of the last week. The study used the version adapted for Mexico (Robles \& Páez, 2003), which obtained a high internal congruence according to Cronbach's alpha coefficients $\alpha=.85$ for positive affect and $\alpha=.81$ for negative affect, in addition to favorable test-retest reliability indicators $(r=.31)$. The internal consistencies obtained for the ARS in this study were appropriate (total $\alpha=.77$ and $\omega=.80$, NA $\alpha=.84$ and $\omega=.85$, and PAf $\alpha=.88$ and $\omega=.88$ ).

\subsection{Procedure}

The people who agreed to take part signed the informed consent previously approved by the ethical commission of the university, according to the regulations on research with human beings in psychology. Subsequently, the participants responded to the instruments; the researcher was present to resolve doubts and ensure ethical responsibilities. The approximate response time of the instruments was 20 minutes. Responses were tabulated in a database and the documents passed into reserved custody. For the preparation of the data, we verified whether the Variation Coefficient was less than 3, as a cut-off point, to assume multivariate normality $(z=$ 
Table 1

Demographic characteristics of participants and groups performed

\begin{tabular}{lcccc}
\hline Variable & Women & Men & Under 25 years & Over 25 years \\
\hline Age & & & & \\
$n=502$ & $\mathrm{M}=25.89(18-40)$, & $\mathrm{M}=26.96(18-40)$, & $\mathrm{M}=21.57(18-25)$, & $\mathrm{M}=32.22(26-40)$, \\
$\mathrm{M}=26.32(18-40), \mathrm{SD}=6.25$ & $\mathrm{SD}=6.30$ & $\mathrm{SD}=6.13$ & $\mathrm{SD}=2.08$ & \\
& & & & $\mathrm{~S}=4.40$ \\
Sex & & & $n=224,44.62 \%$ & $n=103,46 \%$ \\
$n=502,100 \%$ & $n=297,59.2 \%$ & $n=205,40.8 \%$ & $\mathrm{n}=102,36.7 \%$ & $\mathrm{n}=121,54 \%$ \\
& & & $\mathrm{n}=176,63.3 \%$ & \\
Educational level & & & & $n=6,2.7 \%$ \\
Primary $n=18,3.6 \%$ & & & $n=12,4.3 \%$ & $n=33,14.7 \%$ \\
Intermediate $n=84,16.7 \%$ & $n=47,15.8 \%$ & $n=37,18 \%$ & $n=51,18.3 \%$ & $n=56,25 \%$ \\
Technical $n=123,24.5 \%$ & $n=72,24.2 \%$ & $n=51,24.9 \%$ & $n=67,24.1 \%$ & $n=126,56.3 \%$ \\
Higher $n=271,54 \%$ & $n=168,56.6 \%$ & $n=103,50.2 \%$ & $n=145,52.2 \%$ & $n=221,98.7 \%$ \\
Total $n=496,98.8 \%$ & $n=294,99 \%$ & $n=202,98.5 \%$ & $n=275,98.9 \%$ & $n=3,1.3 \%$ \\
Lost data $n=6,1.2 \%$ & $n=3,1 \%$ & $n=3,1.5 \%$ & $n=3,1.1 \%$ &
\end{tabular}

Note. M(Mean), SD(Standard deviation). Source created by the authors.

1.96), as a prerequisite for factor analysis using structural equations.

Confirmatory factorial analysis. R-Proyect lavaan 0.6-3 was used, employing a maximum likelihood method, which makes it possible to compare fit indexes of various factor models; likewise, modeling indicators with structural equations were used to evaluate the models by defining whether the data structure fits previous theoretical assumptions. To determine the fit of each model, Satorra-Bentler's chi-square approximation of goodness-of-fit (S-B $\chi^{2}$ ), Comparative Fit Index (CFI), Tucker Lewis Index (TLI) with expected values greater than .90 as a favorable fit, Root Mean Square Error Approximation (RMSEA), and Standardized Root Mean Square Residual (SRMR) were also calculated, with expected values of less than .08 (Hu \& Bentler, 1999). The Akaike's and Bayesian information criterion (AIC and $\mathrm{BIC}$ ) were used as recommended methods to select the best-confirmed model (Li-Chung, Po-Hsien, \& Li-Jen, 2017).

Analysis of Invariance. The analysis of the model for the conformed groups, with a method of maximum likelihood, was started with configural invariance (verifies equivalences between factors and factorial loads), then metric (verifies equivalences in factorial loads), scalar (checks equivalences from progressive constraint on intercepts to identify scalar differences), and strict (checks by progressive constraint on intercepts for differences in response profiles in item groups), to establish the level of similarity between groups in terms of measurement parameters and structure (Byrne \& van de Vijver, $2010)$, reviewing $\Delta \mathrm{S}-\mathrm{B} \chi^{2}$ variations, among the factorial models for each nested group. A $\Delta \mathrm{CFI} \leq 0.01$ and $\Delta \mathrm{RMSEA} \leq 0.015$ cut-off point is recommended to ac- cept the invariance between each progressive restriction (Chen, 2007).

Concurrent criterion validity. The study established as a hypothesis that the measures of AN, APs, and rumination-anger are predictors of the scores of the RPQ as a criterion, when obtaining significant values of explained variance an indicator of favorable concurrent validity was assumed, in a model supported in investigations on aggression and its causal variables (Peters et al., 2015; White \& Turner, 2014). In this study, we used zero-order correlations and multiple linear regressions by successive steps, analyzing the variations in $R^{2}$ and the coefficients $\beta$ (IC95\%) values that indicated the association of affect and rumination-anger in aggression.

\section{Results}

The preparation of the data set for multivariate analysis was carried out. The Mardia Coefficient was higher than 3 as a cut-off point to assume multivariate normality (multivariate kurtosis $=122.65, z=1.96, p<.001$ ), the set of variables presented abnormality (Yuan, Marshall, \& Bentler, 2002). The analysis was therefore executed with the comparative scaled values of Satorra-Bentler (S-B $\left.\chi^{2}\right)$, recommended for these types of distributions with continuous scales (Satorra \& Bentler, 2010).

\subsection{Confirmatory Factorial Analysis of the RPQ}

This study used the combined values RMSEA and SRMR as adjustment indicators ( $\mathrm{Hu} \&$ Bentler, 1999). Table 2 shows the goodness fit indexes obtained. The onedimensional and two factor non-correlated model presented the least favorable indicators. AIC and BIC were estimated, in which the lowest value indicates the best 
model. In this study, it was the two dimensional with two interrelated and covariant factors; however, once the modification indexes were subsequently revised and residual covariances were implemented among the items that belonged to the same factor, better model fit indicators were obtained.

\subsection{Invariance by Sex and Age of the RPQ}

The confirmed model was reviewed in each nested group imposing progressive and sequential restrictions. Table 3 shows the $\chi^{2}$ and S-B $\chi^{2}(p<.01$ y .001) values. The results suggest that the models should be rejected for statistically significant differences, although this indicator has been questioned for its sensitivity to sample size, the analysis of the progressive variations for each restriction imposed was continued, given that conclusions based only on the p-value may lead to the rejection of parsimonious and theoretically acceptable models. The R-CFI, R-TLI, R-RMSEA, and SRMR values showed optimal settings for the male group and under 25 years of age, while they were not acceptable for the other groups.

In the review of configural invariance, the models are within the acceptance margins for nested groups by sex $(\mathrm{R}-\mathrm{CFI}=0.905$, R-RMSEA $=0.049 \mathrm{CI} 90 \%=0.03$ $0.058)$ and age $(\mathrm{RCFI}=0.891, \mathrm{R}-\mathrm{RMSEA}=0.049 \mathrm{CI} 90 \%=$ 0.03-0.058); it can be stated that the unrestricted models were equivalent in their factor loads, intercepts, and covariances. In the metric invariance, by imposing restrictions on factor loads, minor differences were obtained to $\mathrm{CFI}=0.01$ and $\triangle \mathrm{RMSEA} \leq 0.015$, that is, the $\mathrm{RPQ}$ is invariant in its factors. When imposing a progressive restriction in the intercepts, a scalar invariance was obtained (strong); the values $\triangle \mathrm{CFI}=-0.039$ and $\triangle \mathrm{RMSEA} \leq 0.015$ in sex indicated that the test is not invariant at a scalar level. Therefore, the response profiles and structure were not similar between the sexes, while by age they were invariant. In the last restriction on structural waste to achieve strict invariance, the differences, $\Delta \mathrm{CFI} \leq 0.01$ and $\triangle \mathrm{RMSEA} \leq 0.015$, showed that the groups are not invariant, that is, the differences in responses between groups of items are not due solely to differences in latent factors.

\subsection{Validity of Concurrent Criteria and Reliability of the RPQ}

We found statistically significant correlations of Pearson $(p<.001)$ between total RPQ and AN $(r=.359)$, and rumination-anger $(r=.542)$, as well as a lower negative correlation $(p<.05)$ with PAf $(r=-.088)$. In turn, in the RA and PA the correlations were significant $(p<.001)$ with rumination-anger $(r=.542 ; r=.359)$ and NA $(r=.359 ; r=.211)$, and lower $(p<.05)$ with PAf $(r=-$ $.182 ; r=-.088)$. In multiple regression by successive steps, we found that the predictors of aggression $\left(A R^{2}=.270\right.$, $\mathrm{RMSE}=5.210$ ) were rumination-anger (intercept 20.983, $\beta=.286, \beta$ IC95\% $=0.233-0.338, p<.001)$ and the NA $(\beta=.090, \beta$ IC95\% $=0.022-0.158, p<.01)$.

Finally, the reliability indicators according to the internal consistency of the RPQ were favorable for both subscales of the RPQ (RA: $\alpha=.83, \omega=.83$; PA: $\alpha=.82$, $\omega=.83)$ and the total of the instrument $(\alpha=.88, \omega=.89)$.

\section{Discussion}

The objective of the study was to analyze the factor structure of the RPQ and its invariance according to sex and age in a Colombian sample. According to the data obtained in the verification of the evaluated models, and the analysis of the structure of the test imposing sequential restrictions, it can be affirmed that the objective was achieved.

It was confirmed that the structure with two interrelated factors and residual covariances has the best adjustment indicators regarding the other models, that is, aggression is constituted as a construct that can be measured by the RPQ from two dimensions, reactive and proactive aggression (Andreu et al., 2009; Raine et al., 2006), which allow the assessment of mixed aggression (Penado et al., 2014), as both are correlated $(r=.663$, $p<.001)$. Also, this confirmed model coincides with previous cross-cultural reports (e.g Brugman et al., 2017; Fung et al., 2009; Pechorro et al., 2017; Tuvblad et al., 2016; Dinić \& Raine, 2019).

Therefore, the RPQ maintains a structure of two factors correlated in this study with a Colombian sample, that is, it represents new evidence of the initial model of Dodge and Coie (1987) and Raine et al. (2006), with structural adjustment values similar, although lower, than those reported in Spain (Andreu et al., 2009). These results contradict the structure suggested by Smeets et al. (2016) of three factors, AP, RA because of frustration, and RA because of external provocation, or that suggested by Brugman et al. (2017) of a four-factor RPQ, Impulsive RA before the frustration or provocation, instrumental AP, Aggression in the context of games, and defensive AR. However, despite the reports of these two studies carried out with latent class analysis, these authors believe that the proposal of two dimensions of aggression remains theoretically solid.

The correlations between the RPQ and ruminationanger measures allow us to affirm that they coincide with transdiagnostic studies on externalizing psychopathologies, in particular, in the predictive capacity of ruminationanger and AN in the development of aggressive behaviors (Peters et al., 2015; White \& Turner, 2014). It can be affirmed that the RPQ presents predictive capacity in a regression model, and is constituted as new evidence of the validity of a concurrent criterion of the instrument, although it is necessary to deepen this hypothesis with greater precision.

However, this instrument appears to have better measurement accuracy in the male sample as the RPQ 


\section{Table 2}

Demographic characteristics of participants and groups performed

\begin{tabular}{lccccccccc}
\hline Model & $\chi^{2}$ & S-B $\chi^{2}$ & Df & CFI & TLI & $\begin{array}{c}\text { RMSEA } \\
(\text { IC90\%) }\end{array}$ & SRMR & AIC & BIC \\
\hline Unifactorial & $944.193^{* * *}$ & $590.921^{* * *}$ & 230 & .806 & .787 & $.071(.064-.078)$ & .069 & 12543.914 & 12834.997 \\
Two factors uncorrelated & $1074.057^{* * *}$ & $652.895^{* * *}$ & 230 & .766 & .743 & $.078(.071-.085)$ & .173 & 12673.777 & 12964.861 \\
Two factors correlated & $805.708^{* * *}$ & $503.319^{* * *}$ & 253 & .852 & .837 & $.062(.054-.069)$ & .067 & 12407.428 & 12702.730 \\
Two factors correlated & $558.152^{* * *}$ & $352.291^{* * *}$ & 253 & .928 & .916 & $.044(.036-.053)$ & .056 & 12183.872 & 12529.797 \\
and residual covariances & & & & & & & & & \\
\hline
\end{tabular}

Note. Source created by the authors. ${ }^{* * *} p<.001$

Table 3

Invariance model fit parameters of the $R P Q$ across groups

\begin{tabular}{|c|c|c|c|c|c|c|c|c|c|c|}
\hline $\begin{array}{l}\text { Groups } \\
\text { and } \\
\text { invariance }\end{array}$ & $\chi^{2}$ & S-B $\chi^{2}$ & $d f$ & $\begin{array}{l}R- \\
T L I\end{array}$ & $\begin{array}{l}R- \\
C F I\end{array}$ & $\begin{array}{c}R-R M S E A \\
(C I 90 \%)\end{array}$ & $S R M R$ & $\Delta S-B \chi^{2}$ & \multicolumn{2}{|c|}{$\Delta C F I \Delta R-R M S E A$} \\
\hline Female & $588.516^{* * *}$ & $376.783^{* * *}$ & 253 & .795 & .825 & $.062(.052-.073)$ & .079 & & & \\
\hline Male & $341.231^{* * *}$ & $225.857^{* * *}$ & 253 & .988 & .990 & $.017(.000-.041)$ & .055 & & & \\
\hline Configural & $929.747^{* * *}$ & $605.150 * * *$ & 434 & .889 & .905 & $.049(.039-.058)$ & .069 & - & - & - \\
\hline Metric & $963.041^{* * *}$ & $616.598^{* * *}$ & 455 & .898 & .909 & $.047(.037-.056)$ & .076 & 16.012 & .004 & -.002 \\
\hline Scalar & $1077.542^{* * *}$ & $713.815^{* * *}$ & 476 & .862 & .870 & $.055(.046-.063)$ & .082 & 299.307 & $\begin{array}{c}- \\
.039\end{array}$ & .008 \\
\hline Strict & $1584.699^{* * *}$ & $938.097 * * *$ & 499 & .727 & .731 & $.077(.069-.084)$ & .129 & 93.924 & $\begin{array}{c}- \\
.139\end{array}$ & .022 \\
\hline $\begin{array}{l}\text { Under } 25 \\
\text { years }\end{array}$ & $411.590^{* * *}$ & $286.572^{* *}$ & 217 & .926 & .936 & $.041(.027-.053)$ & .059 & & & \\
\hline $\begin{array}{l}\text { Over } 25 \\
\text { years }\end{array}$ & $543.475^{* * *}$ & $305.912^{* * *}$ & 217 & .845 & .867 & $.057(.041-.071)$ & .071 & & & \\
\hline Configural & $955.065^{* * *}$ & $594.533^{* * *}$ & 434 & .906 & .891 & $.049(.039-.058)$ & .065 & - & - & - \\
\hline Metric & $1034.971^{* * *}$ & $621.421^{* * *}$ & 455 & .888 & .899 & $.049(.039-.059)$ & .082 & 27.682 & .007 & .001 \\
\hline Scalar & $1074.169^{* * *}$ & $657.625^{* * *}$ & 476 & .885 & .892 & $.050(.40-.059)$ & .084 & 41.754 & $\begin{array}{c}- \\
.007\end{array}$ & .001 \\
\hline Strict & $1246.262^{* * *}$ & $778.077^{* * *}$ & 499 & .835 & .837 & $.060(.051-.068)$ & .099 & 179.687 & $\begin{array}{c}- \\
.055\end{array}$ & .010 \\
\hline
\end{tabular}

Note. Source created by the authors. ${ }^{* * *} p<.001$

data was not invariant, in line with findings in Spain where they reported significant variations in male scores (Andreu et al., 2009), suggesting a propensity for aggression by males (Dinić \& Raine, 2019). Nevertheless, these findings contradict other studies with Asian samples that did not report variations in scores (Ang, Huan, Li, \& Chan, 2016), suggesting that aggression would be associated with varying attitudes toward aggression in each culture and social role, also because of differences between socioeconomic statuses according to sexes and their relationship with aggressive responses (Fung et al., 2018). In this way, the proactive and reactive aggressive behavior measured with the RPQ can serve as a valid and reliable tool for evaluating adolescent males involved in criminal or judicial problems, externalizing dysfunctional behaviors, and psychopathic behaviors in different ethnicities (Colins, 2016).

In terms of age differences, the RPQ resulted in a better adjustment in those under 25 years of age; these findings coincide with the differences in test scores (Pang et al., 2013). Despite the low factor adjustment indicators obtained for those over 25 years of age, the RPQ may be appropriate to more accurately assess RA and PA in adolescents and adults under 25 years of age (Lobbestael, Cima, \& Arntz, 2013), which is consistent with different studies of high scores in children under 16 years of age associated with subsequent clinically significant long-term behavioral problems (Raine et al., 2006). Consequently, age would be a significant predictor of aggressive behaviors, especially in adolescents and subsequent development of delinquent behaviors and relapse into adulthood (Fung et al., 2018; Swogger, Walsh, Christie, Priddy, \& Conner, 2015), particularly those with PA (Pechorro et al., 2017).

Although proactive aggressive behaviors may predict elevated psychopathy in adulthood, it is not conclusive, and factors such as maturity may affect adolescent followup scores (Cauffman, Skeem, Dmitrieva, \& Cavanagh, 
2016), perhaps because of the increasing maturity of the prefrontal cortex during adolescence and the gradual regulation of impulsive aggression (Fung et al., 2009), and the deficiencies in empathic cognitive and affective capacity reported by people with high levels of PA and RA (Euler, Steinlin, \& Stadler, 2017).

These obvious differences in the indicators of invariance represent new lines of research of the RPQ in female samples and adults over 25 years of age, as stated by Raine et al. (2006), when reporting inconsistencies in the generalization for these population groups, according to the available literature. However, these findings do not allow us to conclude that RPQ is not a reliable measure for the differential assessment of PA and RA in adolescents or adults, and in this respect, it has been indicated that RPQ is viable for the forensic and general population (Brugman et al., 2017).

\subsection{Limitations and Recommendations}

This study presented some limitations that are recognized here. First, the use of a cross-sectional design did not allow us to track the measurements as a way of verifying its stability, nor did we observe variations in age changes using alternative methods complementary to psychometric analysis, such as latent class analysis and longitudinal tracking, or the use of measures other than self-reporting as a complement to the measurement of aggressive behaviors of the participants.

A second limitation was not being able to obtain a sample of participants with clinical diagnoses associated with high aggressive behaviors such as antisocial psychopathologies, which would allow establishing differential hypotheses in the test scores, nor having analyzed their sensitivity and specificity, which would be useful to be able to discriminate by RA and PA groups in programs for the prevention of aggressive behavior or juvenile delinquency (Fung et al., 2018).

In conclusion, this study found that the best model of aggression fits the two dimensional model of aggression and this is evidence of the theoretical model of the RPQ.

These measures may vary in women and adults over 25 years of age, possibly because of cultural factors such as attitudes towards aggression or maturity because of age changes, aspects that will need to be further investigated in the future.

\section{References}

Andreu, J., Peña, M., \& Ramírez, J. (2009). Cuestionario de agresión reactiva y proactiva: Un instrumento de medida de la agresión en adolescentes. Revista de Psicopatología y Psicología Clínica, 14 (1), 37-49. Retrieved from: http://www.aepcp.net/arc/(4)_2009(1)_Andreu_Pena_Ramirez.pdf.

Ang, R. P., Huan, V. S., Li, X., \& Chan, W. T. (2016). Factor structure and invariance of the reactive and proactive aggression questionnaire in a large sample of young adolescents in Singapore. Child Psychiatry and Human Development, 47(6), 883889. doi:10.1007/s10578-015-0619-y.

Barker, E. D., Tremblay, R. E., Nagin, D. S., Vitaro, F., \& Lacourse, E. (2006). Development of male proactive and reactive physical aggression during adolescence. Journal of Child Psychology and Psychiatry, 47(8), 783-790. doi:10.1111/j.14697610.2005.01585.x.

Brugman, S., Cornet, L. J., Smeijers, D., Smeets, K., Oostermeijer, S., Buitelaar, J. K., \& Jansen, L. M. (2017). Examining the reactive proactive questionnaire in adults in forensic and non-forensic settings: A variable-and person-based approach. Aggressive Behavior, 43(2), 155-162. doi:10.1002/ab.21671.

Byrne, B. M., \& van de Vijver, F. J. R. (2010). Testing for measurement and structural equivalence in largescale cross-cultural studies: Addressing the issue of nonequivalence. International Journal of Testing, 10(2), 107-132. doi:10.1080/15305051003637306.

Cauffman, E., Skeem, J. L., Dmitrieva, J., \& Cavanagh, C. (2016). Comparing the stability of psychopathy scores in adolescents versus adults: How often is "fledgling psychopathy" misdiagnosed? Psychology Public Policy and Law, 22(1), 77-91. doi:10.1037/law0000078.

Chen, F. F. (2007). Sensitivity of goodness of fit indexes to lack of measurement invariance. Structural Equation Modeling: A Multidisciplinary Journal, $14(3), 464-304$. doi:10.1080/10705510701301834.

Colins, O. F. (2016). Assessing Reactive and Proactive Aggression in Detained Adolescents Outside of a Research Context. Child Psychiatry \& Human Development, 47(1), 159-172. doi:10.1007/s10578015-0553-z.

Crick, N. R., \& Dodge, K. A. (1996). Social informationprocessing mechanisms in reactive and proactive aggression. Child Development, 67, 993-1002. doi: $10.2307 / 1131875$.

Dinić, B. M., \& Raine, A. (2019). An Item Response Theory Analysis and Further Validation of the Reactive-Proactive Aggression Questionnaire (RPQ): The Serbian Adaptation of the RPQ. Journal of Personality Assessment, 1-11. doi:10.1080/00223891.2019.1573430.

Dodge, K. A., \& Coie, J. D. (1987). Social-informationprocessing factors in reactive and proactive aggression in childre's peer groups. Journal of Personality and Social Psychology, 53(6), 1146-1158. doi:10.1037/0022-3514.53.6.1146.

Euler, F., Steinlin, C., \& Stadler, C. (2017). Distinct profiles of reactive and proactive aggression in adolescents: Associations with cognitive and affective empathy. Child and Adolescent Psychiatry and Mental Health, 11(1), 1. doi:10.1186/s13034-016- 
0141-4.

Fung, A. L. C., Li, X., Ramírez, M. J., Lam, B. Y., Millana, L., \& Fares-Otero, N. E. (2018). A crossregional study of the reactive and proactive aggression of youth in Spain, Uruguay, mainland China, and Hong Kong. Social Development, 27(4), 748 760. doi:10.1111/sode.12305.

Fung, A. L. C., Raine, A., \& Gao, Y. (2009). Cross-cultural generalizability of the ReactiveProactive Aggression Questionnaire (RPQ). Journal of Personality Assessment, 91(5), 473-479. doi:10.1080/00223890903088420.

Hu, L., \& Bentler, P. M. (1999). Cutoff criteria for fit indexes in covariance structure analysis: Conventional criteria versus new alternatives. Structural Equation Modeling: A multidisciplinary Journal, 6, 1-55. doi:10.1080/10705519909540118.

Hubbard, J. A., McAuliffe, M. D., Morrow, M. T., \& Romano, L. J. (2010). Reactive and proactive aggression in childhood and adolescence: Precursors, outcomes, processes, experiences and measurement. Journal of Personality, 78(1), 95-118. doi:10.1111/j.1467-6494.2009.00610.x.

Li-Chung, L., Po-Hsien, H., \& Li-Jen, W. (2017). Selecting path models in sem: A comparison of model selection criteria. Structural Equation Modeling: A multidisciplinary Journal, 24(6), 855-869. doi:10.1080/10705511.2017.1363652.

Lobbestael, J., Cima, M., \& Arntz, A. (2013). The Relationship Between Adult Reactive and Proactive Aggression, Hostile Interpretation Bias, and Antisocial Personality Disorder. Journal of Personality Disorders, 27(1), 53-66. doi:10.1521/pedi.2013.27.1.53.

Marsee, M. A., \& Frick, P. J. (2007). Exploring the cognitive and emotional correlates to proactive and reactive aggression in a sample of detained girls. Journal of Abnormal Child Psychology, 36 (6), 969981. doi:10.1007/s10802-007-9147-y.

Ortega-Andrade, N., Alcázar-Olán, R., Matías, O. M., Rivera-Guerrero, A., \& Domínguez-Espinosa, A. (2017). Anger rumination scale: Validation in mexico. The Spanish Journal of Psychology, 20(e1), 1-9. doi:10.1017/sjp.2016.105.

Pang, J. S., Ang, R. P., Kom, D. M. Y., Tan, S. H., \& Chiang, A. Q. M. (2013). Patterns of reactive and proactive aggression in young adolescents in singapore. Social Development, 22(4), 794-812. doi:10.1111/sode.12024.

Pechorro, P., Kahn, R. E., Ray, J. V., Raine, A., \& Gonçalves, R. A. (2017). Psychometric Properties of the Reactive-Proactive Aggression Questionnaire among a sample of detained and community girls. Criminal Justice and Behavior, 44(4), 531-550. doi:10.1177/0093854816686395.

Penado, M., Andreu, J. M., \& Peña, E. (2014). Agre- sividad reactiva, proactiva y mixta: análisis de los factores de riesgo individual. Anuario de Psicología Jurídica, 24, 37-42. doi:10.1016/j.apj.2014.07.012.

Peters, J. R., Smart, L. M., Eisenlohr-Moul, T. A., Geiger, P. J., Smith, G. T., \& Baer, R. A. (2015). Anger rumination as a mediator of the relationship between mindfulness and aggression: The utility of a multidimensional mindfulness model. Journal of Clinical Psychology, 71(9), 871-884. doi:10.1002/jclp. 22189.

Raine, A., Dodge, H., Loeber, R., Gatzke-Kopp, L., Lynam, D., Reynolds, C., \& Liu, J. (2006). The Reactive-Proactive Aggression Questionnaire: Differential correlates of reactive and proactive aggression in adolescent boys. Aggressive Behavior, 32(2), 159-171. doi:10.1002/ab.20115.

Robles, R., \& Páez, F. (2003). Estudio sobre la traducción al español y las propiedades psicométricas de las escalas de afecto positivo y negativo (PANAS). Salud Mental, 26(1), 69-75. Retrieved from: http://www.redalyc.org/articulo.oa?id=58212608.

Satorra, A., \& Bentler, P. M. (2010). Ensuring positiveness of the Scaled Difference Chi-square Test Statistic. Psychometrika, 75(2), 243-248. doi:10.1007/s11336-009-9135-y.

Smeets, K. C., Oostermeijer, S., Lappenschaar, M., Cohn, M., van der Meer, J. M., Popma, A., \& Buitelaar, J. K. (2016). Are Proactive and Reactive Aggression Meaningful Distinctions in Adolescents? A Variable-and Person-Based Approach. Journal of abnormal child psychology, 45(1), 1-14. doi:10.1007/s10802-016-0149-5.

Stoltz, S., Cillessen, A. H. N., van der Berg, I. H. M., \& Gommans, R. (2016). Popularity differentially predicts reactive and proactive aggression in early adolescence. Aggressive Behavior, 42, 2940. doi:10.1002/ab.21603.

Sukhodolsky, D. G., Golub, A., \& Cromwell, E. N. (2001). Development and validation of the anger Rumination Scale. Personality and Individual Differences, 31, 689-700. doi:10.1016/S0191-8869(00)00171-9.

Swogger, M. T., Walsh, Z., Christie, M., Priddy, B. M., \& Conner, K. R. (2015). Impulsive versus premeditated aggression in the prediction of violent criminal recidivism. Aggressive Behavior, 41, 346352. doi:10.1002/ab.21549.

Tuvblad, C., Dhamija, D., Berntsen, L., Raine, A., \& Liu, J. (2016). Cross-cultural validation of the ReactiveProactive Aggression Questionnaire (RPQ) using four large samples from the US, Hong Kong, and China. Journal of Psychopathology and Behavioral Assessment, 38(1), 48-55. doi:10.1007/s10862-0159501-2.

Vitaro, F., Brendgen, M., \& Tremblay, R. E. (2002). Reactively and proactively aggressive children: An- 
tecedent and subsequent characteristics. Journal of Child Psychology and Psychiatry, 43(4), 495-505. doi:10.1111/1469-7610.00040.

Watson, D., Clark, L., \& Tellegen, A. (1988). Development and validation of brief measures of positive and negative affect: the PANAS scales. Journal of Personality and Social Psychology, 54, 1063-1070. doi:10.1037/0022-3514.76.5.820.

White, B. A., \& Turner, K. A. (2014). Anger rumination and effortful control: Mediation effects on reactive but not proactive aggression. Personality and Individual Differences, 56, 186-189. doi:10.1016/j.paid.2013.08.012.

White, S. T., \& Frick, P. J. (2010). Callous - unemotional traits and their importance to causal models of severe antisocial behavior in youths. In R.T. Salekin and D.T. Lynam (eds), Handbook of child and adolescent psychology (pp. 135-156). Nueva York: The Gilford Press.

Yuan, K. H., Marshall, L. L., \& Bentler, P. M. (2002). A unified approach to exploratory factor analysis with missing data, nonnormal data, and in the presence of outliers. Psychometrika, 67(1), 95-121. doi:10.1007/bf02294711. 